Published in final edited form as:

Biomacromolecules. 2017 February 13; 18(2): 483-489. doi:10.1021/acs.biomac.6b01563.

\title{
Drug-loaded Polymeric Spherical Nucleic Acids: Enhancing Colloidal Stability and Cellular Uptake of Polymeric Nanoparticles through DNA Surface-functionalization
}

\author{
Resham J. Banga ${ }^{a}$, Sai Archana Krovi ${ }^{b, d}$, Suguna P Narayan ${ }^{c}$, Anthony J. Sprangers ${ }^{c}$, \\ Guoliang Liu $^{\mathrm{d}, \mathrm{e}}$, Chad A. Mirkin ${ }^{\mathrm{d}, \mathrm{f}}$, and SonBinh T. Nguyen ${ }^{\mathrm{d}, \mathrm{f},{ }^{*}}$ \\ aDepartment of Chemical and Biological Engineering, Northwestern University, 2145 Sheridan \\ Road, Evanston, Illinois-60208-3113, USA \\ 'Department of Biomedical Engineering, Northwestern University, 2145 Sheridan Road, \\ Evanston, Illinois-60208-3113, USA \\ dDepartment of Chemistry, Northwestern University, 2145 Sheridan Road, Evanston, \\ Illinois-60208-3113, USA \\ fInternational Institute of Nanotechnology, Northwestern University, 2145 Sheridan Road, \\ Evanston, Illinois-60208-3113, USA
}

\section{Abstract \\ Small-sized ( $\sim 65 \mathrm{~nm}$ ) doxorubicin (Dox)-loaded polymeric nanoparticles (PNPs) were modified with oligonucleotides to form colloidally stable Dox-loaded polymeric spherical nucleic acid (Dox-PSNA) nanostructures in biological media. The nucleic acid shell facilitates the cellular uptake of Dox-PSNA, resulting in in-vitro cytotoxicity against SKOV3 cancer cells.}

\section{TOC figure}

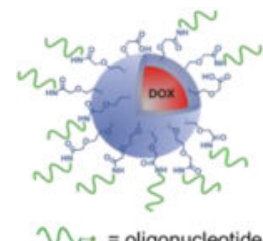

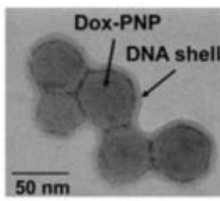

TEM image

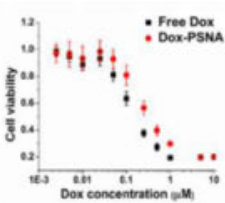

$I_{S_{0}}$ of Dox-PSNA

“Corresponding Author: stn@northwestern.edu.

bCurrent address: UNC Eshelman School of Pharmacy, University of North Carolina at Chapel Hill, 301 Pharmacy Lane Beard Hall, Chapel Hill, North Carolina 27599;

${ }^{\mathrm{e}}$ Current address: Department of Chemistry, Virginia Tech, Blacksburg, Virginia 24061, USA;

\section{SUPPORTING INFORMATION}

The Supporting Information is available free of charge on the ACS Publications website at DOI: 10.1021/acs.biomac.

General experimental and instrumentation details; procedures for the syntheses of monomers, homopolymers, block copolymers, and cholesterol-loaded PNPs; characterization data for monomers, homopolymers, block copolymers, and cholesterol-loaded PSNAs; stability data for Dox-PSNAs in serum and cell culture media; $\mathrm{pH}$-dependent drug release profiles for Dox-PSNAs; quantification of cellular uptake of Dox-PSNA and free doxorubicin (PDF).

Notes: The authors declare no competing financial interest. 


\section{Keywords}

Drug-loaded nanoparticles; polymeric nanoparticles; spherical nucleic acids; doxorubicin; ringopening metathesis polymerization

Polymeric nanoparticles (PNPs) prepared from amphiphilic ROMP block copolymers $(\mathrm{ROMP}=$ ring-opening metathesis polymerization) represent a versatile class of multifunctional nanoconstructs for biodetection, ${ }^{1,2}$ imaging, ${ }^{3}$ and drug delivery. ${ }^{4,5}$ In particular, the ease with which these nanoparticles can be surface-functionalized ${ }^{2}$ with a multitude of biologically active entities ${ }^{2,6}$ has shown promise in many drug delivery applications. ${ }^{5,7,8}$ Previously, we reported that ROMP-based doxorubicin-loaded PNPs can be modified with cationic surface moieties post-assembly to improve their stability in buffered media and in vitro cellular uptake. ${ }^{7}$ However, the large diameters of these particles $(\sim 100$ $200 \mathrm{~nm}$ ) may limit their cellular uptake ${ }^{9}$ and tumor penetration when delivered in vivo. ${ }^{10,11}$ Thus, we set out to improve the bioavailability of the doxorubicin-loaded PNP platform by reducing nanoparticle size and covalently modifying the surface with negatively charged oligonucleotides, which have been shown to promote higher cellular uptake. ${ }^{12}$ Since sub-100 $\mathrm{nm}$-sized nanoparticles have been shown to exhibit increased cellular uptake and better penetration into tumor tissue, ${ }^{13,14}$ these two modifications may allow for extended stability under physiologically relevant conditions and should enhance overall efficacy for in vivo applications.

The high-density surface modification of nanoparticles with oligonucleotides results in a three-dimensional architecture known as a spherical nucleic acid (SNA). ${ }^{12}$ The dense oligonucleotide shells in SNAs have been shown to stabilize a broad range of nanoparticle cores-from inorganic $\mathrm{Au},{ }^{15} \mathrm{Ag},{ }^{16}$ and silica ${ }^{17}$ ones to organic structures such as ultra-small liposomes, ${ }^{18}$ proteins, ${ }^{19}$ and polymers ${ }^{20,21}$-under physiological conditions via electrostatic repulsion. ${ }^{18}$ The SNA architecture also promotes superior cellular internalization for the nanoparticle cores over PEG-functionalized analogs ${ }^{22}$ and linear nucleic acids, ${ }^{23}$ given its ability to bind to cellular membrane-bound scavenger receptors, ${ }^{23}$ which facilitate cellular internalization via endosomal pathways. ${ }^{12,24}$ As a result, SNA structures have been utilized in a wide variety of applications spanning biodetection, ${ }^{22}$ gene regulation ${ }^{25}$, drug delivery, ${ }^{26-28}$ and immunomodulation. ${ }^{12,29}$ By covalently modifying small (sub-100 nm) doxorubicin-loaded PNPs with oligonucleotides (Scheme 1), we show herein that the resulting doxorubicin-loaded polymeric SNA (Dox-PSNA) structures are stable under physiologically relevant conditions, are capable of active cellular internalization, and exhibit cytotoxicity with respect to SKOV-3 ovarian cancer cells. While the potency of these DoxPSNA nanoparticles is comparable to that of the free drug, they should not be prone to the renal clearance issues that plague small molecules. ${ }^{30}$

\section{MATERIALS AND METHODS}

\section{Materials and Instrumentation}

Please see SI, Section S1 


\section{Synthesis of block copolymer $2_{15}-b-1_{15}$}

In an inert-atmosphere glovebox, monomer 2 (25 mg, $45.2 \mu \mathrm{mol}$; see SI, Section S2 for the synthesis of monomer 2$)$ was dissolved in an anhydrous mixture of $\mathrm{CHCl}_{3} / \mathrm{MeOH}(9: 1 \mathrm{v} / \mathrm{v}, 1$ $\mathrm{mL}$ ) in a $20 \mathrm{~mL}$ scintillation vial equipped with a magnetic stir bar. A stock solution of Grubbs' first-generation catalyst $(5 \mathrm{mg})$ in $\mathrm{CHCl}_{3} / \mathrm{MeOH}(9: 1 \mathrm{v} / \mathrm{v}, 5 \mathrm{~mL})$ was prepared, a portion of which $(2.48 \mathrm{~mL}, 3.01 \mu \mathrm{mol})$ was added to the vial containing the solution of monomer 2 under vigorous stirring. The resulting reaction mixture was stirred for $45 \mathrm{~min}$ at room temperature, at which time an aliquot $(100 \mu \mathrm{L})$ was removed and quenched with excess ethyl vinyl ether. A portion of this quenched aliquot was evaporated to dryness, redissolved in $\mathrm{CDCl}_{3}$, and analyzed by ${ }^{1} \mathrm{H} \mathrm{NMR}$ spectroscopy, which indicated complete consumption of the monomer. The remaining portion was evaporated to dryness, dissolved in HPLC-grade THF, and subjected to GPC analysis $\left(M_{\mathrm{n}}=9000\right.$ (theoretical $\left.M_{\mathrm{n}}=8000\right)$, $\mathrm{PDI}=1.13)$.

Immediately after aliquot removal, a solution of monomer 1 (see SI, Section S1, $30.7 \mathrm{mg}$, $45.2 \mu \mathrm{mol})$ in $\mathrm{CHCl}_{3} / \mathrm{MeOH}(9: 1 \mathrm{v} / \mathrm{v}, 1 \mathrm{~mL})$ was added to the reaction vial and the resulting polymerization mixture was stirred for an additional $45 \mathrm{~min}$ before being terminated with the addition of ethyl vinyl ether $(1 \mathrm{~mL})$. The reaction mixture was added quickly into vigorously stirred cold $\left(-10{ }^{\circ} \mathrm{C}\right)$ pentanes $(200 \mathrm{~mL})$, and the resulting precipitate was isolated via vacuum-filtration and washed thoroughly with fresh pentanes to afford the product copolymer quantitatively as a red solid. See the SI for the ${ }^{1} \mathrm{H}$ NMR spectrum, Section S3). Due to the lack of complete polymerization of monomer 1 when being initiated as the first block, 7,31 we did not attempt to synthesize the reverse block copolymer $\mathbf{1}_{15^{-}}$ $b-2_{15}$.

To maximize the number of chemical handles that can subsequently be used for surface functionalization of the PNPs, we employed a block copolymer with an equimolar ratio of monomers 2:1, while keeping the PNP diameter $<100 \mathrm{~nm}$.

\section{General procedure for the preparation of PNPs in the $60-75 \mathrm{~nm}$ size range}

An aqueous suspension of the polymer nanoparticles was prepared by dialysis following a modification of the published procedure. ${ }^{7}$ An aliquot $(2.5 \mathrm{~mL})$ of a stock solution of block copolymer $\mathbf{2}_{15}-b-\mathbf{1}_{15}(0.01 \mathrm{wt} \%)$ in DMSO was transferred to a $4 \mathrm{~mL}$ scintillation vial and stirred vigorously. Ultrapure deionized water was added to this stirring copolymer solution at a rate of 1 drop $(50 \mu \mathrm{L}, 1.75 \mathrm{wt} \%)$ every $1 \mathrm{~s}$ using a $20-100 \mu \mathrm{L}$ micro-pipette until the mixture contained $18 \mathrm{wt} \%$ water. The resulting cloudy mixture was placed in a $3 \mathrm{~mL}$ dialysis cassette and dialyzed against ultrapure deionized water $(500 \mathrm{~mL})$, with the dialate changed every $2 \mathrm{~h}$. Complete absence of DMSO in the dialysate after $48 \mathrm{~h}$ was verified by $\mathrm{UV}$-vis spectroscopy as indicated by the disappearance of the UV cut-off for DMSO at 268 nm.

\section{Characterization of PNPs derived from block copolymer $2 \mathbf{2}^{-b-1_{15}}$}

DLS analysis of the final PNP aqueous suspension derived from block copolymer $\mathbf{2}_{15}-b-\mathbf{1}_{15}$ revealed relatively monodisperse PNPs with an average $D_{\mathrm{H}}=63 \pm 7 \mathrm{~nm}$ and a PDI $=0.11$ (Figure 1B). TEM analysis indicated a uniform size distribution for the PNPs in the solid- 
state, with an average diameter of $\sim 65 \mathrm{~nm}$ (Figure 1C) that is consistent with the DLS data. The zeta potential of these PNPs was determined to be $-6.83 \pm 0.5 \mathrm{mV}$. The average concentration of PNP particles is $\sim 1 \times 10^{10}$ particles $/ \mathrm{mL}$, as determined by NTA. The doxorubicin loading for the PNPs is $64 \mathrm{wt} \%$, as calculated based on the doxorubicin wt $\%$ in the $\mathbf{2}_{15} \boldsymbol{b} \boldsymbol{b}-\mathbf{1}_{15}$ copolymer.

\section{DNA functionalization of doxorubicin-loaded PNPs and characterization data}

In a $1.5 \mathrm{~mL}$ safe-lock Eppendorf tube, solutions of $N$-(3-dimethylaminopropyl)- $N^{\prime}$ ethylcarbodiimide hydrochloride $(\mathrm{EDC} \cdot \mathrm{HCl}$, final concentration in reaction solution $=5$ $\mu \mathrm{M}$ ) and $N$-hydroxysulfosuccinimide (sulfo-NHS, final concentration in reaction solution $=$ $7.5 \mu \mathrm{M})$ in ultrapure deionized water were added to an aliquot $(1 \mathrm{~mL})$ of the carboxyfunctionalized PNP suspension $\left(1 \times 10^{10}\right.$ particles $/ \mathrm{mL}, \sim 125,000$ carboxylate groups $)$ derived from the desired block copolymer. The reaction mixture was agitated (1000 rpm) on a multi-therm platform shaker (Benchmark Scientific, Inc., South Plainfield, NJ, USA) for 5 min at room temperature. A freshly prepared aliquot of $3^{\prime}$-amino-terminated oligonucleotides ( $100 \mu \mathrm{L}$ of a $10 \mu \mathrm{M}$ solution) was then added to the reaction mixture, and the resulting mixture was covered with aluminum foil and agitated on a multi-therm platform shaker for $4 \mathrm{~h}$ at room temperature.

To increase the density of oligonucleotide packing on the PNP surface, EDC and NHS solutions (to $5 \mu \mathrm{M}$ and $7.5 \mu \mathrm{M}$ final concentrations, respectively, assuming that all the initially added reagents have been consumed/decomposed) were added to the PNP solution, and the resulting mixture was subjected to a salt-aging process. ${ }^{32}$ Aliquots of $\mathrm{NaCl}(8 \mu \mathrm{L}$ of a $5 \mathrm{M}$ solution to attain a final $[\mathrm{NaCl}]=50 \mathrm{mM}$ ) were added to the reaction mixture every $30 \mathrm{~min}$, and the Eppendorf tube was sonicated for $15 \mathrm{~s}$ (Branson 2510 ultrasonic cleaner, Branson Ultrasonics, Danbury, CT, USA) after each salt addition. Upon reaching a total $\mathrm{NaCl}$ concentration of $300 \mathrm{mM}$, the reaction mixture was agitated on a multi-therm platform shaker for an additional $12 \mathrm{~h}$ at room temperature. The resulting PSNAs were then purified using size-exclusion chromatography (Sepharose CL-4B, Sigma Aldrich). The average concentration of PSNA particles was $\sim 10^{9} / \mathrm{mL}$, as determined by NTA.

\section{Characterization of oligonucleotides-conjugated doxorubicin-loaded PNPs}

DLS analysis of the final DNA-functionalized PNP aqueous suspension derived from block copolymer $\mathbf{3}_{15}-b-\mathbf{5}_{15}$ revealed relatively monodisperse PNPs with an average $D_{\mathrm{H}}=88 \pm 3$ $\mathrm{nm}$ and $\mathrm{a}$ PDI $=0.13$. The zeta potential of the oligonucleotide-modified PNPs was determined to be $-31.2 \pm 3.2$, indicating that negatively charged oligonucleotides are conjugated to the PNP surface. For TEM analysis, the PNPs were pre-stained with uranyl acetate solution $(10 \mu \mathrm{L}, 2 \% \mathrm{w} / \mathrm{v})$.

\section{Quantification of oligonucleotides strands on the surface of PSNAs}

To assess the degree of oligonucleotide surface modification, an aliquot $(20 \mu \mathrm{L})$ of the purified Cy5-oligonucleotide-modified PNPs was added to DMSO solution and placed on a multi-therm shaker for $2 \mathrm{~h}$ at $37^{\circ} \mathrm{C}$ to dissolve the PSNAs. An aliquot ( $\left.50 \mu \mathrm{L}\right)$ of the resulting solution was further mixed with DMSO (final volume $=200 \mu \mathrm{L}$ ), and its fluorescence at the emission wavelength of Cy5 $\left(\lambda_{\mathrm{ex}}=649 \mathrm{~nm}, \lambda_{\mathrm{em}}=670 \mathrm{~nm}\right)$ was 
recorded using a Synergy HT multi-mode microplate reader (BioTek, Winooski, VT, USA). This fluorescence was compared against a calibration curve constructed from absorbance values for solutions of the Cy5-labeled oligonucleotides in DMSO (concentrations $=0,0.1$, $0.25,0.5,1,2.5,5 \mu \mathrm{M})$. From this analysis and the number of PSNA nanoparticles in solution (obtained from NTA), each cholesterol-containing PSNA particle was estimated to have 1900 oligonucleotides strands and each doxorubicin-loaded PSNA particle was estimated to have $\sim 1200$ oligonucleotides strands. The doxorubicin loading is $63.8 \mathrm{wt} \%$, as calculated based on the doxubicin wt $\%$ in the $\mathbf{2}_{15}-\boldsymbol{b}-\mathbf{1}_{15}$ copolymer and the total weight of the DNA, assuming an average density of 1 for the whole construct.

\section{Stability study of PNPs and PSNAs}

Two separate aliquots of the doxorubicin-containing PNPs and PSNAs $(500 \mu \mathrm{L})$ were transferred to a $1.5 \mathrm{~mL}$ safe-lock Eppendorf tube and centrifuged for $30 \mathrm{~min}$ at $10 \mathrm{~K} \mathrm{rpm}$ to a solid pellet. The supernatant was removed and the PNPs were re-suspended in PBS (500 $\mu \mathrm{L}$, $10 \mathrm{mM}, \mathrm{pH} 7.4,150 \mathrm{mM}[\mathrm{NaCl}])$. As expected, characterization of the PNP suspension in PBS resulted in loss of the original well-defined morphology of the parent PNPs as observed by TEM and DLS. The size of PSNAs was analysed periodically over a two month period using DLS. We note in passing that while single-stranded DNA has been adsorbed to the surface of polymer nanoparticles through non-covalent modification, ${ }^{33,34}$ such constructs have not been tested for stability in cell culture media.

\section{Melt Analysis}

Melt analysis experiments were carried out using a Cary 5000 UV-vis spectrometer equipped with a programmable heating stage (ThermoFisher Scientific, Carlsbad, CA, USA). Doxorubicin-containing PSNAs functionalized with Melt A strands were prepared as described above. $13 \mathrm{~nm}$ Au-core SNAs functionalized with the complementary Melt B strands (Table S1) were prepared following literature protocols. ${ }^{32}$ The aggregates were formed by combining these two materials in a 1:1 ratio (total DNA concentration $=1.5 \mu \mathrm{M}$, total volume $=1 \mathrm{~mL}$ ). The aggregates were then subjected to a temperature ramp from 20 to $65^{\circ} \mathrm{C}$ (rate of $0.25^{\circ} \mathrm{C} / \mathrm{min}$ ) while the absorbance for the aggregates was continuously monitored at $260 \mathrm{~nm}$.

\section{Cell culture experiments}

SKOV-3 cells were purchased from American Tissue Culture Collection (ATCC, Manassas, VA, USA) and grown in McCoy's 5A medium (Invitrogen, Carlsbad, CA, USA) supplemented with $10 \%$ heat-inactivated fetal bovine serum, penicillin (100 IU/mL), and streptomycin $(50 \mu \mathrm{g} / \mathrm{mL})$ and maintained at $37^{\circ} \mathrm{C}$ with $5 \% \mathrm{CO}_{2}$ as per ATCC instructions. For cellular studies, the cells were plated at $60 \%$ confluency $24 \mathrm{~h}$ prior to the treatment.

\section{Confocal microscopy of PSNAs}

In a typical experiment, SKOV-3 cells were plated on a $35 \mathrm{~mm}$ FluoroDish (World Precision Instruments, Saratosa, FL, USA) and incubated for $24 \mathrm{~h}$ before being transfected with the appropriate oligonucleotide formulation (final DNA concentration $=0.1 \mu \mathrm{M}$ ). The treated cells were incubated for $24 \mathrm{~h}$ before being washed three times with $1 \times$ phosphate-buffered 
saline (PBS, Invitrogen) and imaged under a Zeiss LSM 510 inverted laser-scanning confocal microscope using Hoechst 33342 as a nuclear stain. The fluorescence excitation for Cy5 was set as $630 \mathrm{~nm}$ and emission $650-710 \mathrm{~nm}$. For Z-stack images, the images were collected in different planes with a depth of $0.3 \mu \mathrm{M}$.

\section{Cellular uptake experiments}

The cellular uptake of the PSNAs was compared to that of the free drug in SKOV3 cells. In preparation for this analysis, the cells were seeded at $60 \%$ confluency in a 96 well plate $24 \mathrm{~h}$ before treatment with PSNAs and free doxorubicin. The treatments were carried out at 0.1 , $0.5,1$, and $2.5 \mu \mathrm{M}$ of doxorubicin. The cells were then incubated with either free drug or the PSNAs for $24 \mathrm{~h}$ before washing three times with $1 \times$ PBS. The cells were then detached from the plate surface by exposing to trypsin $(20 \mu \mathrm{L})$ for 5 mins and fixed using a $4 \%$ paraformaldehyde solution (in $1 \times$ PBS). The intracellular delivery of doxorubicin was quantified via flow cytometry on a Guava easyCyte $8 \mathrm{HT}$ instrument (Millipore, Billerica, MA, USA) using the doxorubicin channel and normalized based on the intensity of the untreated cells.

\section{Cell viability studies for doxorubicin and Dox-PSNAs}

SKOV-3 (ovarian cancer) cells were seeded in 96 well plates at a density of $\sim 5000$ cells per well $24 \mathrm{~h}$ before the experiment. Cells were incubated with a fixed amount $(100 \mu \mathrm{L})$ of solution containing either doxorubicin or Dox-PSNAs that were prepared at varying concentrations in OptiMEM (Invitrogen) at $37^{\circ} \mathrm{C}$. After overnight incubation, the media was replaced with regular growth medium (McCoy's 5A supplemented with $10 \%$ heatinactivated fetal bovine serum, penicillin $(100 \mathrm{IU} / \mathrm{mL})$, and streptomycin $(50 \mu \mathrm{g} / \mathrm{mL}))$, and the cells were incubated at $37{ }^{\circ} \mathrm{C}$ for an additional $48 \mathrm{~h}$. Cell viability was assessed using the alamarBlue ${ }^{\circledR}$ cell viability assay (ThermoFisher Scientific, Carlsbad, CA, USA) according to the manufacturer's recommended protocol. Briefly, $10 \%$ alamarBlue ${ }^{\circledR}$ reagent in regular growth medium was added to cells ( $100 \mu \mathrm{L}$ per well), and the treated cell plate was incubated at $37^{\circ} \mathrm{C}$ for $4 \mathrm{~h}$ before being analyzed on a Synergy $\mathrm{H} 4$ Multimode Microplate Reader. Fluorescence data at $570 \mathrm{~nm}$ were collected and normalized to that for an untreated control. Reported values represent the mean \pm standard deviation of 5 replicates.

\section{RESULTS AND DISCUSSION}

As a general strategy, ${ }^{35}$ ROMP-based PNPs were assembled from short amphiphilic block copolymers consisting of one hydrophobic doxorubicin-conjugated block and a hydrophilic carboxy-terminated, poly(ethylene oxide) (PEO)-loaded block (Figure 1). With this design, the doxorubicin-loaded block constitutes the core of the PNPs, and the PEO-loaded segment forms a shell with terminal carboxy groups that can be used for further surface modification. The doxorubicin payload was linked to the hydrophobic segment through an acid-cleavable linkage ${ }^{4}$ which can be released in the low-pH environment of the late endosome ${ }^{36}$ or in the tumor tissue. ${ }^{37}$

The amphiphilic block copolymers needed for PNP preparation were synthesized by blockcopolymerizing the carboxy-terminated, PEO-conjugated monomer $\mathbf{2}$ and the doxorubicinconjugated monomer $\mathbf{1}$ (Figure 1A). A 15:15 molar ratio for monomers 2:1 was chosen to 
limit the molecular weight of the polymer $<45 \mathrm{kDa}$, thus facilitating renal clearance of the polymers post drug release. ${ }^{38}$ Monomer 2 was successfully homo-polymerized using Grubbs' first-generation olefin metathesis $\left(\left(\mathrm{PCy}_{3}\right)_{2} \mathrm{Cl}_{2} \mathrm{Ru}=\mathrm{CHPh}\right)$ catalyst $(\mathbf{3})$ as confirmed by ${ }^{1} \mathrm{H}$ NMR spectroscopy and gel-permeation chromatography (GPC) analyses $\left(\mathrm{M}_{\mathrm{n}}=9000\right.$ (theoretical $\mathrm{M}_{\mathrm{n}}=8000$ ), polydispersity index (PDI) $=1.17$; Supporting Information (SI), Section S2). Sequential addition of monomer $\mathbf{1}$ to the homo-polymerized block $\mathbf{2}_{15}$, followed by quenching with ethyl vinyl ether resulted in the formation of our desired monodisperse amphiphilic block copolymer $\mathbf{2}_{15}-b-\mathbf{1}_{15}$ (final polymer $\mathrm{M}_{\mathrm{n}}=15000$ (theoretical $\mathrm{M}_{\mathrm{n}}=14000$ ), PDI $=1.12$; see Materials and Methods section and SI, Section S3).

Following our previously established strategy, ${ }^{7}$ dropwise addition of water to a DMSO solution of copolymer $\mathbf{2}_{15^{-}} b-\mathbf{1}_{15}$, followed by exhaustive dialysis against ultrapure deionized water, afforded an aqueous suspension of carboxy-functionalized, doxorubicin-loaded PNPs (Figure 1A). These nanoparticles have small hydrodynamic diameters $\left(D_{H}=63 \pm 7 \mathrm{~nm}\right.$, Figure 1B) and exhibit a narrow size distribution (PDI $=0.11 \pm 0.02)$, as measured by dynamic light scattering (DLS). Transmission electron microscopy (TEM) also confirmed their homogeneous spherical morphology (Figure 1C) with an average $D_{H}$ of $65 \pm 5 \mathrm{~nm}$. Key to the realization of these small nanoparticle sizes was a fast rate of water addition over a shorter time period than previously reported ${ }^{7}$ (see Materials and Methods section).

The covalent surface modification of the carboxy-functionalized PNPs with $3^{\prime}$-amineterminated DNA was achieved using EDC/NHS coupling (Figure 1A). A mixture of the two components was stirred together with the EDC and NHS reagents for $4 \mathrm{~h}$ before being subjected to a salt-aging process to further increase the DNA density on the PNP surface ${ }^{32}$ (see Materials and Methods section). After the total salt concentration reached $0.3 \mathrm{M}$, this mixture was allowed to react further overnight before being purified by size-exclusion chromatography. A TEM image (Figure 1D) of the isolated PSNA clearly shows the retention of the discrete and spherical morphology of the parent PNP (diameter $\sim 87 \mathrm{~nm}$ ). Their DLS-derived size distribution plot (Figure 1B) shows an increase in the hydrodynamic diameter $\left(D_{\mathrm{H}}=88 \pm 3 \mathrm{~nm}\right.$ and PDI $\left.=0.13 \pm 0.03\right)$ that can be attributed to the addition of a dense DNA shell on the PNP surfaces. The shift in zeta potential $(-5.1 \pm 1.5 \mathrm{mV}$ for the parent PNPs) to a higher negative value $(-31.2 \pm 3.2 \mathrm{mV}$ for the PSNAs) also corroborates the successful conjugation of DNA to the PNP surface. Notably, the presence of the DNA shell on the surface of the PNP can be clearly observed upon staining of the PSNAs with uranyl acetate (z-contrast and transmission modes; Figure 1D). While not a primary focus of the current work, the thickness of the DNA shell can be changed by altering the length and composition of the oligonucleotide strands. ${ }^{39}$ On average, 1200 DNA strands/PNP were conjugated to the surface of each PNP as determined by fluorescence spectroscopy and nanoparticle tracking analysis (NTA) to quantify the number of PSNAs in a given sample via light scattering and Brownian motion. This DNA surface density $\left(\sim 7 \mathrm{pmol} / \mathrm{cm}^{2}\right.$, see Materials and Methods section for calculation) is comparable to but slightly higher than the loadings obtained for our previously reported liposomal SNA constructs. ${ }^{40}$

The doxorubicin-loaded PSNAs show excellent stability in comparison to the parent PNPs, a property that enables their use in cellular systems. For example, the PSNAs remain 
colloidally stable after 2 months of incubation in phosphate-buffered saline (1× PBS) at room temperature (Figure 2A). In contrast, subjecting the unmodified PNPs to the same treatment for only a week resulted in formation of polydisperse aggregates irreversibly agglomerated, presumably through interparticle fusion. Most relevant for physiological applications, no change was observed in the DLS distribution plot for the PSNAs after 3 days of incubation at $37^{\circ} \mathrm{C}$ in $1 \times$ PBS (Figures $2 \mathrm{C}$ and 2D). We attribute this enhanced stability to the electrostatic repulsion between the negatively charged oligonucleotides that comprise the shell of the PSNA, which inhibits particle-particle fusion under physiologically relevant conditions. ${ }^{18}$ Notably, Dox-PSNAs remain stable in the presence of human serum while still maintaining their acid-triggered drug-release properties. ${ }^{31}$ The doxorubicin-based fluorescence profiles for Dox-PSNAs after being incubated at $37^{\circ} \mathrm{C}$ in PBS and human serum solution $(10 \% \mathrm{v} / \mathrm{v})$ are very similar as evidenced by minimal leakage of the drug (SI, Figure S8). In contrast, exposing Dox-PSNAs to $0.1 \mathrm{M} \mathrm{HCl}$ (aq) leads to a six-fold increase in drug release after one hour (SI, Figure S8).

Consistent with the assigned SNA structure, PSNAs cooperatively hybridize with complementary Au core SNAs. For example, when PSNAs were combined with complementary $13 \mathrm{~nm}$ Au-core SNAs (Figure 3A), visible aggregates can be observed and isolated. TEM analysis (Figures 3B and 3C) of these hybridized materials clearly shows a complete coverage of the larger PSNAs by the smaller Au-core SNAs. The increase in the melting temperature $\left(\mathrm{T}_{\mathrm{m}}\right.$ of the PNP-AuNP hybrid $=54.7^{\circ} \mathrm{C}$ vs $\mathrm{T}_{\mathrm{m}}=52^{\circ} \mathrm{C}$ (as calculated at $150 \mathrm{mM} \mathrm{NaCl}$ and $1.5 \mathrm{uM}$ oligonucleotides using IDT OligoAnalyzer ${ }^{41}$ ) for the free DNA duplex analog) of these aggregates and their narrow thermal denaturation profile (full width at half-maximum (fwhm) of the first derivative is $\sim 2.3^{\circ} \mathrm{C}$ ) confirms cooperative binding behavior that is characteristic of SNAs ${ }^{15}$ (Figure 3D).

As expected, the dense oligonucleotide shell of the Dox-PSNAs greatly facilitates their entrance into cells. As shown by confocal microscopy, SKOV-3 cells (ovarian cancer ascites) readily uptake Dox-PSNAs that were surface-modified with 5'-Cy5-labelled oligonucleotides (Figure 4A). This is in stark contrast to the non-functionalized PNP analog, which settles out of cell culture media due to aggregation and shows low and non-uniform uptake. ${ }^{31}$ Such enhanced cellular internalization of SNA structures has been attributed by Mirkin and coworkers to the interaction of the oligonucleotide shell with Class A scavenger receptors (SR-A) present on the cell surface, followed by caveolin-mediated endocytosis. ${ }^{23}$ Because our goal was to enhance the delivery of the therapeutically active payload of DoxPSNAs to diseased cells, a generic $\mathrm{T}_{20}$ DNA sequence was sufficient for this purpose. We note in passing that although a detailed mechanistic study comprising competitive and endocytosis inhibition assays can be carried out to ascertain the exact uptake mechanism, such a study is beyond the scope of the present work.

The cellular internalization properties of the Dox-loaded PSNAs (Dox-PSNAs) lead to invitro cytotoxicity against SKOV3 cancer cells that is comparable to that of free doxorubicin (Figure 4B). Such a study could not have been properly carried out with the parent PNPs due to their aggregation behavior in biological media. Indeed, PNPs have been observed to settle out of cell culture media over time, leading to low and non-uniform uptake in SKNSH wildtype cells. ${ }^{31}$ The observed cytotoxicity of the Dox-PSNAs can be attributed to the acid- 
induced cleavage of the carbamate linkage between the block copolymer backbone and the doxorubicin, allowing for the release of the latter into the cytoplasm. ${ }^{6,31}$ Supporting this conclusion is the observation that the analogous PSNAs with cholesterol-loaded cores does not show any cytotoxicity against SKOV3 cells (SI, Section S5).

\section{CONCLUSIONS}

In summary, we have demonstrated that the successful modification of doxorubicin-loaded PNPs with a dense oligonucleotide shell greatly increases their colloidal stability in biological media under physiological conditions. The dense shell of oligonucleotides allows the resulting Dox-PSNAs to have enhanced cellular uptake, manifesting in cytotoxicity that is comparable to the free drug. Importantly, this SNA-based strategy should be generalizable to other therapeutic-loaded nanoparticles for in vivo applications in the treatment of cancer and other diseases.

\section{Supplementary Material}

Refer to Web version on PubMed Central for supplementary material.

\section{Acknowledgments}

Research reported in this publication was supported by the Center for Cancer Nanotechnology Excellence initiative of the National Cancer Institute of the National Institutes of Health under Award Number U54CA151880 and U54CA199091. This material is also based upon work supported by the AFOSR under Award No. FA9550-12-1-0280. CAM additionally acknowledges support from the NTU-NU Institute for NanoMedicine located at the International Institute for Nanotechnology, Northwestern University, USA and the Nanyang Technological University, Singapore. Instruments in the Northwestern University IMSERC, Keck Biophysics, and EPIC/NUANCE facilities were purchased with grants from NSF-NSEC (NSF EEC-0647560), NIH-CCNE, NSFMRSEC (NSF DMR-1121262), the Keck Foundation, the State of Illinois, and Northwestern University. We additionally thank the reviewers of the initial version of this manuscript for comments that help improving its quality. The content of this work is solely the responsibility of the authors and does not necessarily represent the official views of the National Institutes of Health or the AFOSR.

\section{ABBREVIATIONS}

$\begin{array}{ll}\text { Dox } & \text { doxorubicin } \\ \text { DH }_{\text {H }} & \text { hydrodynamic diameters } \\ \text { DLS } & \text { dynamic light scattering } \\ \text { NTA } & \text { nanoparticle tracking analysis } \\ \text { PDI } & \text { polydispersity index } \\ \text { PEG } & \text { poly(ethylene glycol) } \\ \text { PNP } & \text { polymeric nanoparticles } \\ \text { PSNA } & \text { polymeric spherical nucleic acids } \\ \text { ROMP } & \text { ring-opening metathesis polymerization }\end{array}$




\section{References}

1. Rush AM, Nelles DA, Blum AP, Barnhill SA, Tatro ET, Yeo GW, Gianneschi NC. J Am Chem Soc. 2014; 136:7615-7618. [PubMed: 24827740]

2. Bertin PA, Gibbs JM, Shen CK, Thaxton CS, Russin WA, Mirkin CA, Nguyen ST. J Am Chem Soc. 2006; 128:4168-4169. [PubMed: 16568958]

3. Allen MJ, Raines RT, Kiessling LL. J Am Chem Soc. 2006; 128:6534-6535. [PubMed: 16704234]

4. Bertin PA, Smith D, Nguyen ST. Chem Commun. 2005; 41:3793-3795.

5. Callmann CE, Barback CV, Thompson MP, Hall DJ, Mattrey RF, Gianneschi NC. Adv Mater. 2015; 27:4611-4615. [PubMed: 26178920]

6. Krovi SA, Smith D, Nguyen ST. Chem Commun. 2010; 46:5277-5279.

7. Krovi SA, Swindell EP, O’Halloran TV, Nguyen ST. J Mater Chem. 2012; 22:25463-25470. [PubMed: 23509417]

8. Mukherjee S, Patra D, Dinda H, Chalkraborty I, Shashank L, Bhattacharyya R, Das Sarma J, Shunmugam R. Macromolecules. 2016; 49:2411-2418.

9. Huang K, Ma H, Liu J, Huo S, Kumar A, Wei T, Zhang X, Jin S, Gan Y, Wang PC, He S, Zhang X, Liang XJ. ACS Nano. 2012; 6:4483-4493. [PubMed: 22540892]

10. Choi JS, Cao J, Naeem M, Noh J, Hasan N, Choi HK, Yoo JW. Colloids Surf, B. 2014; 122:545551.

11. Tang L, Gabrielson NP, Uckun FM, Fan TM, Cheng J. Mol Pharmaceutics. 2013; 10:883-892.

12. Cutler JI, Auyeung E, Mirkin CA. J Am Chem Soc. 2012; 134:1376-1391. [PubMed: 22229439]

13. Cabral H, Matsumoto Y, Mizuno K, Chen Q, Murakami M, Kimura M, Terada Y, Kano MR, Miyazono K, Uesaka M, Nishiyama N, Kataoka K. Nat Nanotechnol. 2011; 6:815-823. [PubMed: 22020122]

14. Biondi M, Guarnieri D, Yu H, Belli V, Netti PA. Nanotechnology. 2013; 24:045101. [PubMed: 23293277]

15. Mirkin CA, Letsinger RL, Mucic RC, Storhoff JJ. Nature. 1996; 382:607-609. [PubMed: 8757129]

16. Lee JS, Lytton-Jean AK, Hurst SJ, Mirkin CA. Nano Lett. 2007; 7:2112-2115. [PubMed: 17571909]

17. Young KL, Scott AW, Hao L, Mirkin SE, Liu G, Mirkin CA. Nano Lett. 2012; 12:3867-3871. [PubMed: 22725653]

18. Banga RJ, Chernyak N, Narayan SP, Nguyen ST, Mirkin CA. J Am Chem Soc. 2014; 136:98669869. [PubMed: 24983505]

19. Brodin JD, Auyeung E, Mirkin CA. Proc Natl Acad Sci U S A. 2015; 112:4564-4569. [PubMed: 25831510]

20. Peterson AM, Heemstra JM. Wiley Interdiscip Rev: Nanomed Nanobiotechnol. 2015; 7:282-297. [PubMed: 25327363]

21. Jia F, Lu X, Tan X, Zhang K. Chem Commun. 2015; 51:7843-7846.

22. Giljohann DA, Seferos DS, Patel PC, Millstone JE, Rosi NL, Mirkin CA. Nano Lett. 2007; 7:3818-3821. [PubMed: 17997588]

23. Choi CH, Hao L, Narayan SP, Auyeung E, Mirkin CA. Proc Natl Acad Sci U S A. 2013; 110:7625-7630. [PubMed: 23613589]

24. Wu XA, Choi CH, Zhang C, Hao L, Mirkin CA. J Am Chem Soc. 2014; 136:7726-7733. [PubMed: 24841494]

25. Giljohann DA, Seferos DS, Prigodich AE, Patel PC, Mirkin CA. J Am Chem Soc. 2009; 131:2072-2073. [PubMed: 19170493]

26. Dhar S, Daniel WL, Giljohann DA, Mirkin CA, Lippard SJ. J Am Chem Soc. 2009; 131:14652-+. [PubMed: 19778015]

27. Tan X, Li BB, Lu X, Jia F, Santori C, Menon P, Li H, Zhang B, Zhao JJ, Zhang K. J Am Chem Soc. 2015; 137:6112-6115. [PubMed: 25924099]

28. Tan XY, Lu XG, Jia F, Liu XF, Sun YH, Logan JK, Zhang K. J Am Chem Soc. 2016; 138:1083410837. [PubMed: 27522867] 
29. Radovic-Moreno AF, Chernyak N, Mader CC, Nallagatla S, Kang RS, Hao L, Walker DA, Halo TL, Merkel TJ, Rische CH, Anantatmula S, Burkhart M, Mirkin CA, Gryaznov SM. Proc Natl Acad Sci U S A. 2015; 112:3892-3897. [PubMed: 25775582]

30. Kadam RS, Bourne DWA, Kompella UB. Drug Metab Dispos. 2012; 40:1380-1388. [PubMed: 22498894]

31. Smith D, Clark SH, Bertin PA, Mirkin BL, Nguyen ST. J Mater Chem. 2009; 19:2159-2165. [PubMed: 24421587]

32. Hurst SJ, Lytton-Jean AK, Mirkin CA. Anal Chem. 2006; 78:8313-8318. [PubMed: 17165821]

33. Li HL, Sun XP. Chem Commun. 2011; 47:2625-2627.

34. Wang L, Zhang Y, Tian J, Li H, Sun X. Nucleic Acids Res. 2011; 39:e37. [PubMed: 21183465]

35. Bertin PA, Watson KJ, Nguyen ST. Macromolecules. 2004; 37:8364-8372.

36. Deng X, Wang Y, Zhang F, Yin Z, Hu Q, Xiao X, Zhou Z, Wu Y, Sheng W, Zeng Y. Chem Commun. 2016; 52:3243-3246.

37. Poon Z, Chang D, Zhao X, Hammond PT. ACS Nano. 2011; 5:4284-4292. [PubMed: 21513353]

38. Nori A, Kopeček J. Adv Drug Delivery Rev. 2005; 57:609-636.

39. Narayan SP, Choi CH, Hao L, Calabrese CM, Auyeung E, Zhang C, Goor OJ, Mirkin CA. Small. 2015; 11:4173-4182. [PubMed: 26097111]

40. Hill HD, Millstone JE, Banholzer MJ, Mirkin CA. ACS Nano. 2009; 3:418-424. [PubMed: 19236080]

41. https://www.idtdna.com/calc/analyzer; accessed on April 2, 2016.

42. Lee S-M, Chen H, O'Halloran TV, Nguyen ST. J Am Chem Soc. 2009; 131:9311-9320. [PubMed: 19527027] 
A)

15<smiles>O=C(O)COCCOCc1ccc(COc2ccccc2)cc1</smiles>

Monomer 2

15 equivalents
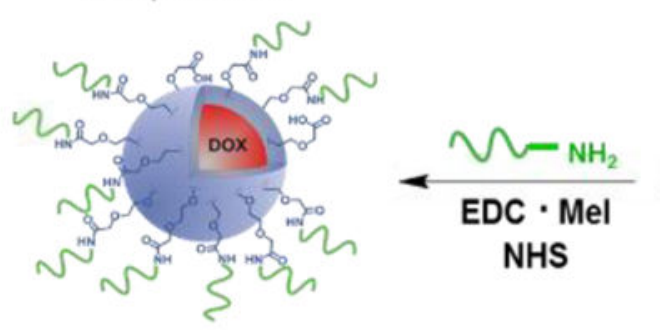

NHS

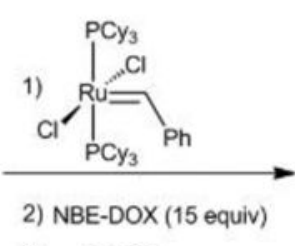

3)

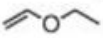

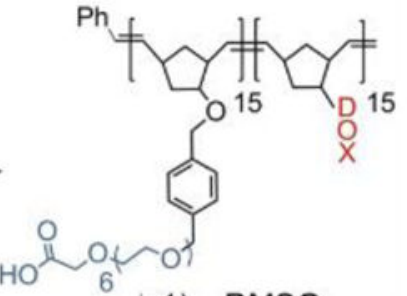

1) $\mathrm{DMSO}$

2) $\mathrm{H}_{2} \mathrm{O}$

、3) Dialysis

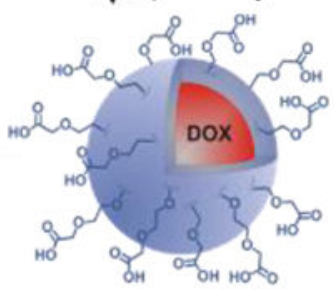

B)

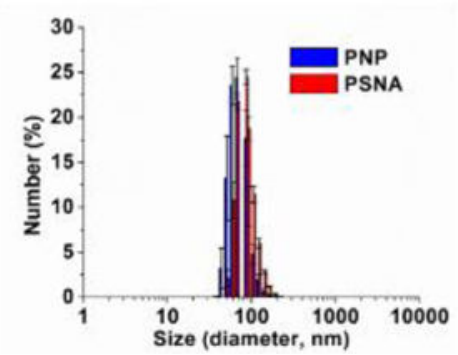

C)

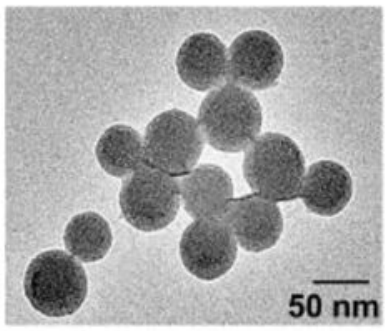

D)

Figure 1.

A) Synthesis of block copolymer $\mathbf{1}_{15}-b-\mathbf{2}_{15}$ and subsequent formation of the corresponding PNPs. B) Dynamic light scattering (DLS) data for the PNPs before and after covalent DNA functionalization. C-D) TEM image of the PNPs before (C) and after (D) DNA functionalization. 
A)
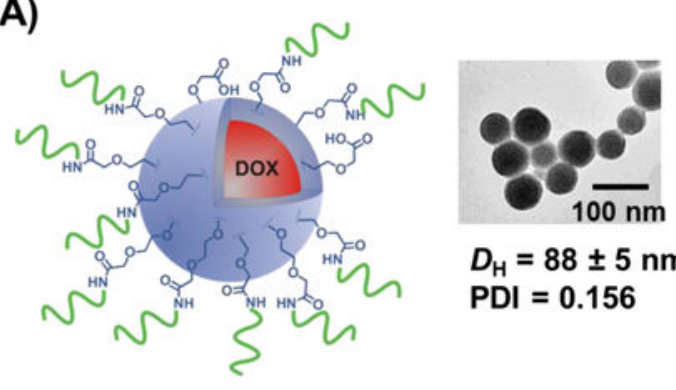

$D_{\mathrm{H}}=88 \pm 5 \mathrm{~nm}$ $\mathrm{PDI}=0.156$

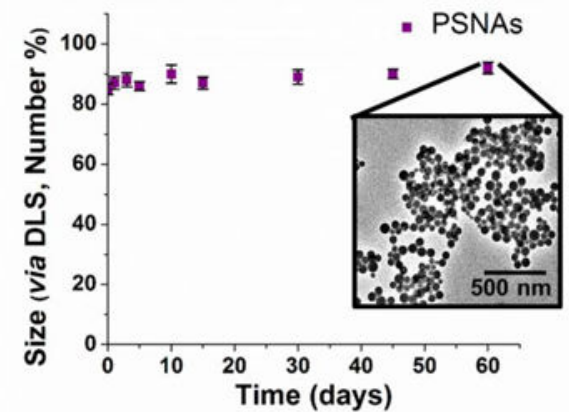

B)
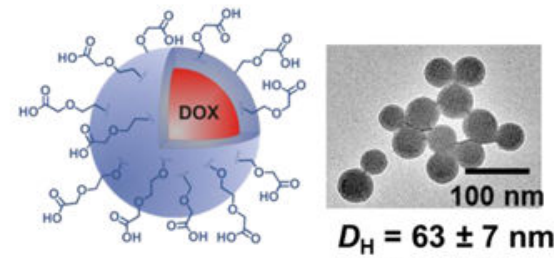

1) Centrifuge

2) Resuspend in $1 x$ PBS for 1 week $\mathrm{PDI}=0.108$

Initial solution in ultrapure DI water

C)

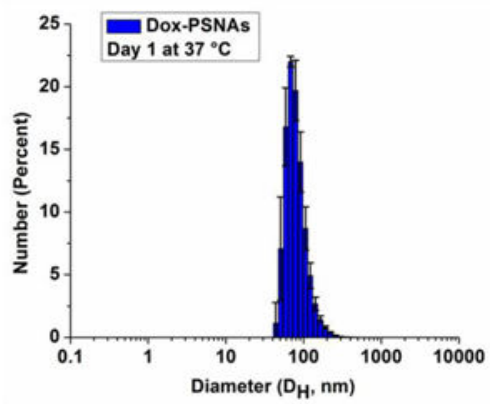

D)

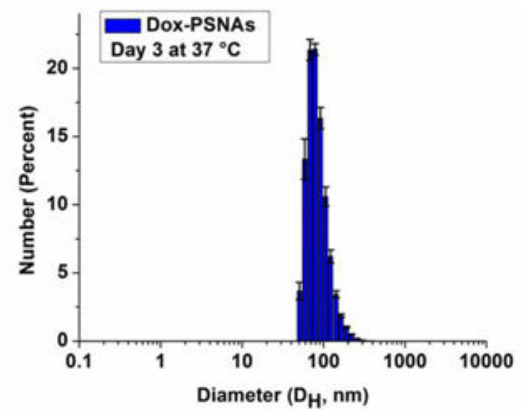

Figure 2.

A) Doxorubicin-loaded PSNAs remain stable for over two months in $1 \times$ PBS as analysed by TEM and DLS. B) Doxorubicin-loaded PNPs aggregate when incubated in $1 \times$ PBS for a week. C and D) DLS profiles for Dox-PSNAs confirming their stablity in $1 \times \mathrm{PBS}$ at $37^{\circ} \mathrm{C}$ for 3 days. 


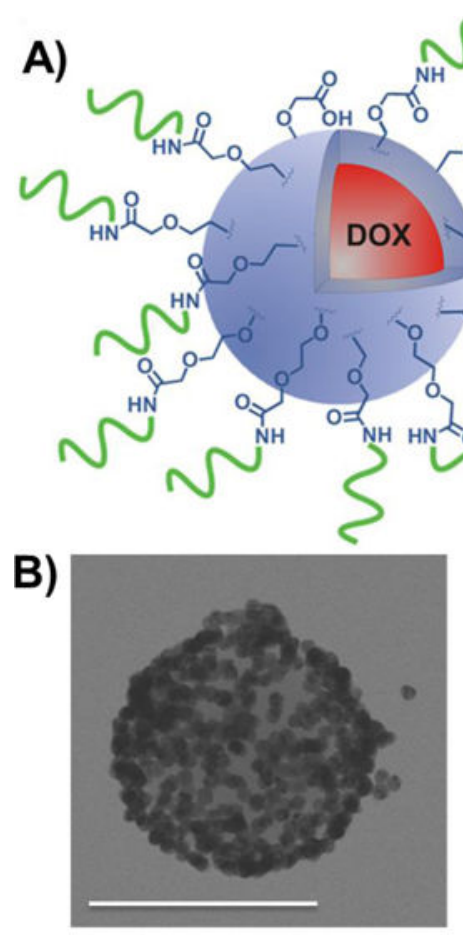<smiles>C1CCC1</smiles><smiles>CCCC(CC)C(C)NC(=O)O</smiles>

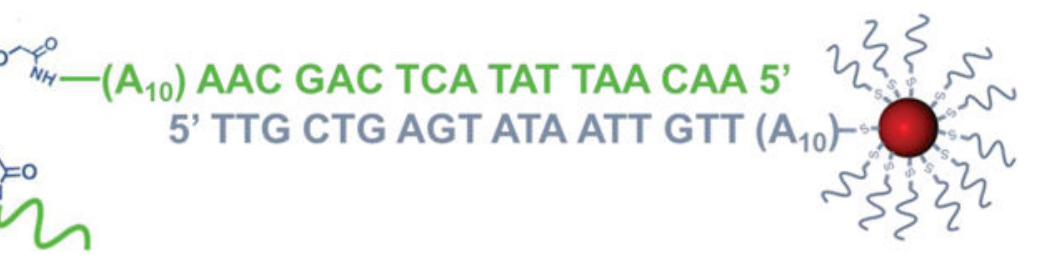

C)

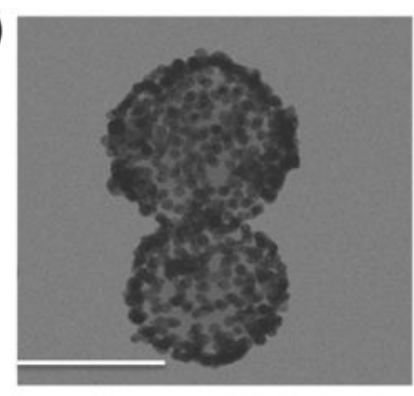

D)

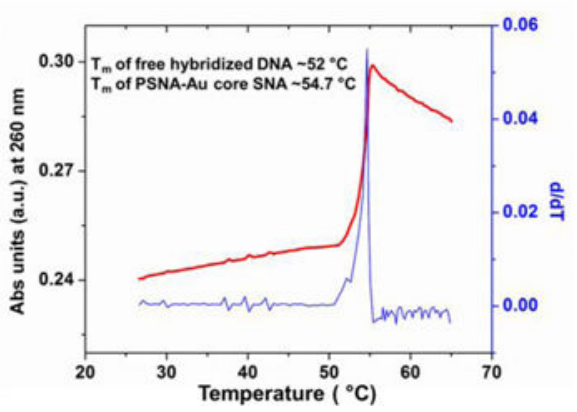

Figure 3.

A) A schematic drawing of the Dox-PSNAs hybridized to complementary $13 \mathrm{~nm}$ Au-core SNAs. B-C) TEM images of the Dox-PSNAs surrounded by complementary Au-core SNAs conjugates. Scale bar is $100 \mathrm{~nm}$. D) The thermal denaturation profile (red) of the [DoxPSNAs + Au-core SNAs] hybridized aggregates monitored as a change in extinction at 260 $\mathrm{nm}$. The overlaid $1^{\text {st }}$ derivative (blue) of this profile shows the sharp melting transition. See SI, section S10 for the control experiment. 

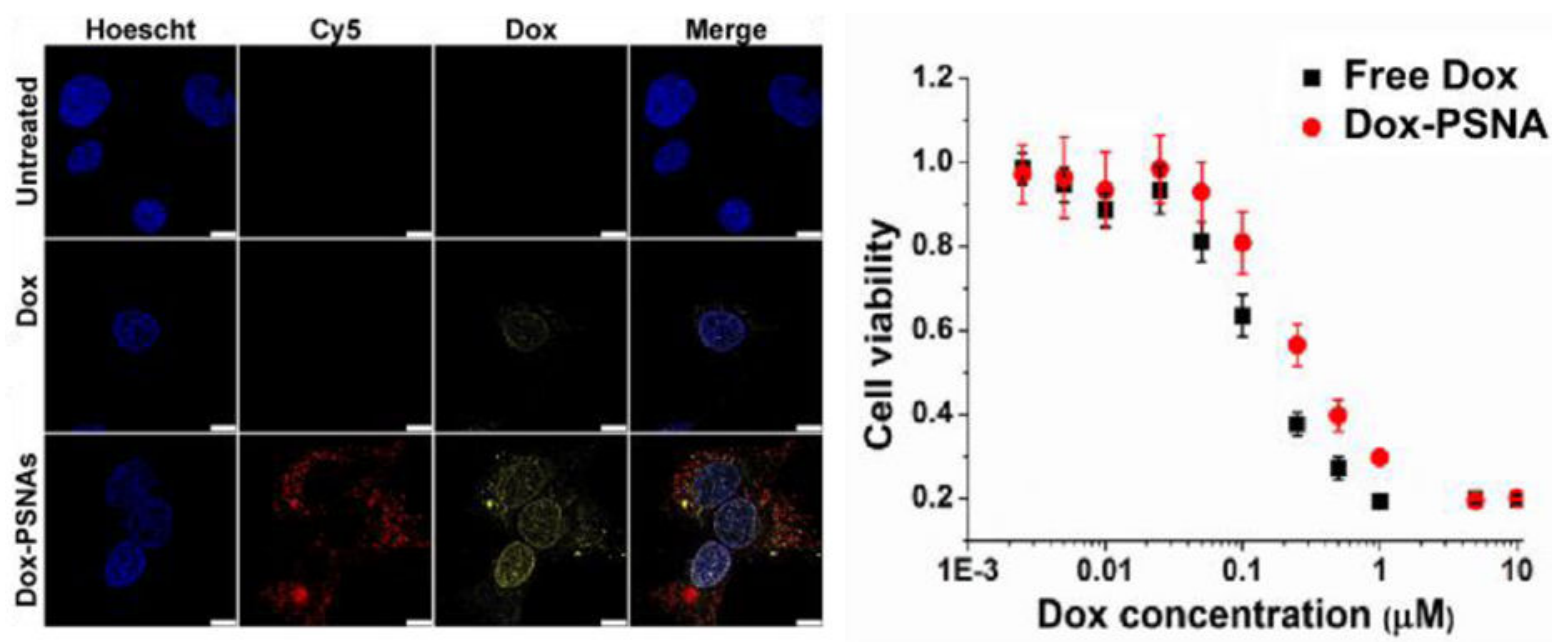

Figure 4.

A) Confocal laser-scanning microscopy images of SKOV-3 cells that have been incubated for $24 \mathrm{~h}$ with free doxorubicin (Dox) and doxorubicin-loaded PSNAs (Dox-PSNAs) at 2.5 $\mu \mathrm{M}$ Dox concentration. Given the qualitative nature of the confocal image (e.g., change in focal point between sample wells), the various signal intensities should not be compared across rows. In addition, each panel is limited to a few cells and do not represent the entire population. A statistically significant flow cytometry study (SI, Figure S10) does show higher doxorubicin fluorescence signal for the cells that have been incubated with free doxorubicin. B) Cytotoxicity profiles for SKOV-3 cells that have been incubated for $48 \mathrm{~h}$ with dox and Dox-PSNA formulations at $5 \mathrm{nM}-10 \mu \mathrm{M}$ [ Dox]. The similarity in toxicity between the doxorubicin-loaded NPs and free doxorubicin is not surprising given previous studies from our group, ${ }^{31,42}$ and the fact that $\mathrm{IC}_{50}$ measurements are highly dependent on many variables (treatment time, incubation time post-treatment, release of payload from the delivery vehicle, cell type and confluency) and can vary by several fold, depending on conditions. 

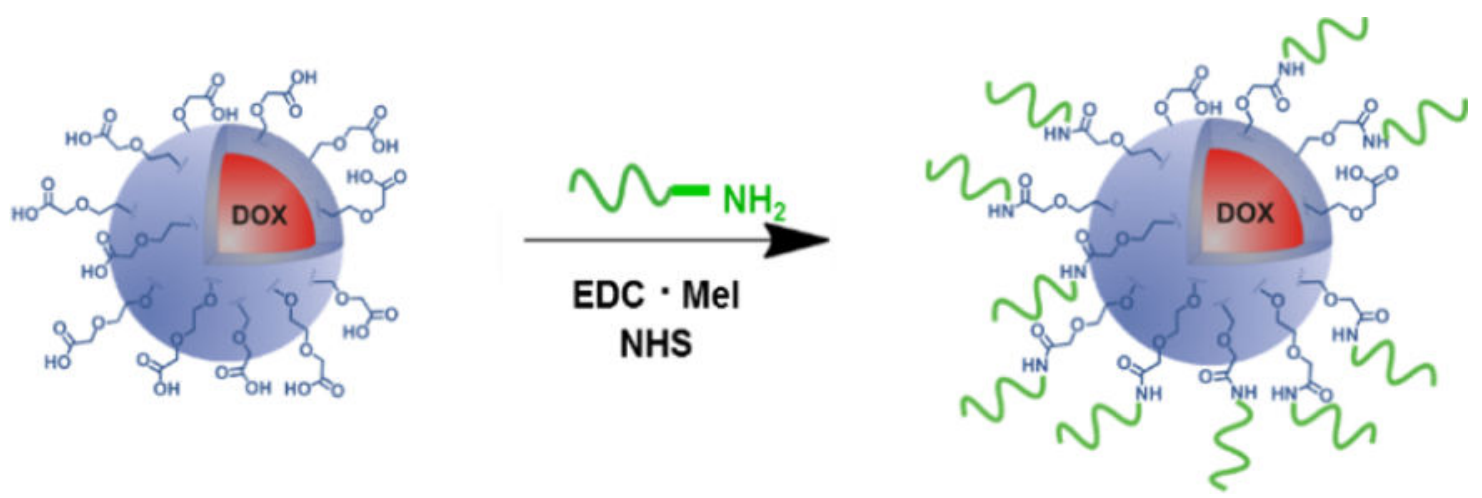

Scheme 1.

The covalent surface modification of carboxy-functionalized PNPs with amine-terminated oligonucleotides (green) via amide-coupling chemistry. 